\title{
EFFECTS OF WORK BURDEN, JOB STRAIN AND SUPPORT ON DEPRESSIVE SYMPTOMS AND BURNOUT AMONG JAPANESE PHYSICIANS
}

\author{
YASUAKI SAIJO ${ }^{1}$, SHIGERU CHIBA ${ }^{2}$, EIJI YOSHIOKA ${ }^{1}$, YASUYUKI KAWANISHI ${ }^{1}$, YOSHIHIKO NAKAGI', \\ TOSHIHIRO ITOH ${ }^{1}$, YOSHIHIKO SUGIOKA ${ }^{1}$, KAZUYO KITAOKA-HIGASHIGUCHI ${ }^{3}$, and TAKAHIKO YOSHIDA ${ }^{1}$ \\ ${ }^{1}$ Asahikawa Medical University, Asahikawa, Japan \\ Department of Health Science \\ ${ }^{2}$ Asahikawa Medical University, Asahikawa, Japan \\ Department of Psychiatry and Neurology \\ ${ }^{3}$ Kanazawa University, Kanazawa, Japan \\ Institute of Medical, Pharmaceutical and Health Sciences
}

\begin{abstract}
Objectives: Days off, on call, night duty, working hours and job stress can affect physicians' mental health, and support from supervisors and co-workers may have a buffering effect. This study elucidates whether job strain and job factors affect physicians' mental health, and whether support from supervisors and co-workers has a protective effect on their mental health. Material and Methods: The subjects included 494 physicians. The Brief Job Stress Questionnaire (BJSQ) was used to evaluate job demand, job control and support. High job strain was defined as a combination of high job demand and low job control. Depressive symptoms were assessed using the Patient Health Questionnaire-9. The Maslach Burnout InventoryGeneral Survey was used to evaluate burnout. Possible confounder adjusted logistic regression analyses were performed to obtain odds ratios for depressive symptoms and burnout. Results: As per the analysis, high job strain had significantly higher odds ratios, and support from co-workers had significant protective odds ratios for depressive symptoms. High job strain and having only 2-4 days off per month (compared to $>8$ days off per month) had significantly higher odds ratios, and support from co-workers had significant protective odds ratios for burnout. Conclusions: High job strain was related to depressive symptoms and burnout, and support from co-workers had a buffering effect on depressive symptoms and burnout. An inadequate number of days off was related to burnout. Assessment of job strain may be a good tool to measure physicians' mental health, and a sufficient number of days off may be needed to prevent burnout.
\end{abstract}

Key words:

Social support, Depressive symptoms, Burnout, Job satisfaction, Job strain, Physician

\section{INTRODUCTION}

Physicians now confront increasing burdens, such as a rapidly expanding knowledge base and increasing clinical demand, which affect their well-being [1]. Japanese hospital physicians tend to have long working hours [2,3], and the shortage of some specialties, such as pediatrics, obstetricsgynecology and surgery, is one of the Japanese health care system problems [4].

Grant-in-Aid for Scientific Research (No. 21590549) from the Japan Society for the Promotion of Science.

Received: January 8, 2014. Accepted: July 18, 2014.

Corresponding author: Y. Saijo, Asahikawa Medical University, Department of Health Science, Midorigaoka-higashi 2-1-1-1 Asahikawa, Hokkaido 078-8510, Japan (e-mail: y-saijo@asahikawa-med.ac.jp). 
Long working hours affect mental health among other work populations [4,5]; and the relationship with physicians' mental health has been reported [6]. Moreover, days off, on call and night duty have been reported to affect physicians' mental health [7,8].

The demand-control-support (DCS) model [9] is a major job stress model that has been widely used in the field of occupational health. The model has 2 dimensions, job demand and job control, with social support being included as a 3rd dimension. Job control among German junior doctors, as estimated by the DCS model, is related to mental health [10]. Job strain means that although demands are high, workers have few opportunities to use their skills and make decisions; it has also been related to depression among Canadian general workers [11]. Among Canadian physicians, job demands have been related to emotional exhaustion and physical symptoms, and resources, including job control, have been related to personal accomplishments and decreased depersonalization [12]. Among German physicians, job strain has been significantly related to their quality of care [13]. However, in Japan, the relationship between job strain and physicians' mental health has not been fully investigated.

It has also been reported that social support at work has a buffering effect on depressive symptoms among London civil servants [14], and that social support from family/friends has a buffering effect on depressive symptoms among Japanese physicians [6]. However, the buffering effect of support from supervisors and co-workers on physicians' mental health has not been fully investigated, either. Burnout is characterized by emotional exhaustion, depersonalization and negative self-evaluation among various professionals involved in people-oriented services, including health care staff such as physicians [15,16]. Physicians' burnout status has been reported to be associated with the intention to change jobs [17], job dissatisfaction [18] and low-quality patient care $[19,20]$. A review described burnout as more job-related and situation-specific than general depression, though depression-prone people are more vulnerable to burnout [16]. Burnout symptoms estimated using the MBI (Maslach Burnout Inventory) are discriminative because exhaustion and depersonalization/reduced professional efficacy are required in the work context [21]. Therefore, burnout is a notable mental health indicator among physicians.

In this study, to elucidate whether job strain affects physicians' mental health and whether support from supervisors and co-workers has a protective effect, these variables were simultaneously introduced in logistic regression models in which outcomes were depressive symptoms and burnout. In addition to this, to elucidate specific work burdens - days off, on call, night duty, and long working hours - which affect physicians' mental health, these variables and support from supervisors and co-workers (but not job strain because it contains work burden) were simultaneously introduced in the logistic regression models.

\section{MATERIAL AND METHODS}

\section{Participants}

We dispatched self-administered questionnaires to the entire alumni population of Asahikawa Medical University ( $N=2937)$ via post in December 2009. These questionnaires had previously been used to study regional differences in job stress and burnout status among hospital physicians [22]. Twenty questionnaires were returned as 'addressee unknown' (valid participants - 2917). Participants could choose to respond to the questionnaires by either filling them out on paper or responding on a website. A post card was sent once as a reminder. Among the valid participants $(\mathrm{N}=2917), 567(19.4 \%)$ responded to the questionnaires (on paper-340; on the website -227). Among the respondents, 517 were hospital or clinic physicians, of which 494 questionnaires were analyzed after excluding 23 because of missing values. 
This study was approved by the Institutional Ethical Board for Epidemiological Studies of Asahikawa Medical University (No. 647: November 30, 2009).

\section{Demographics and work-related factors}

The questionnaire included information on gender, age (ranges: 24-29, 30-39, 40-49, $\geq 50$ years old), marital status, clinical experience (ranges: 0-9, 10-19, $\geq 20$ years), clinical specialty (internal medicine, surgery, pediatrics/obstetrics/gynecology, ophthalmology/dermatology, other/unknown), hospital location (large cities: ordinance-designated cities, prefectural capitals, cities with a medical school or university, medium or small cities, other cities, towns, and villages), days off (0-1, 2-4, 5-7, $\geq 8$ /month), night duty (none, $1,2-3,4-5, \geq 6$ /month), on call (none, 1-4, 5-7, $\geq 8 /$ month), working hours (none, 1-39, 40-49, 50-59, 60-79, $\geq 80 \mathrm{~h} /$ week). The recall period of the final 4 variables was the preceding 1 month.

\section{Job stress and social support}

The Brief Job Stress Questionnaire (BJSQ) [23], which is based on the DCS model [9], was used to evaluate 2 job stress dimensions (job demand and job control) and social support from supervisors and co-workers. The BJSQ also includes support from family/friends, but this was not used because we focused on job factors and needed to restrict independent variables owing to the small sample sizes. The BJSQ has been widely used in Japan for practical occupational health evaluation and occupational health research [24-26]. Job demand included 3 items:

1. You have to do an enormous amount of work.

2. You cannot complete all your work in the allotted time.

3. You have to work very hard.

In addition, there were 3 items about job control:

1. You can work at your own pace.

2. You can decide the order in which you do your work and the way you do it.
3. You can provide your opinions on the work strategy for your workplace.

The responses were scored on a 4-point Likert-type scale (1 - agree; 2 - somewhat agree; 3 - somewhat disagree, and 4 - disagree) [25]. To evaluate job demand and job control, the total score for each dimension was used. Higher scores denote higher job demand or control.

Social support from supervisors, co-workers and family/ friends was also evaluated using 3 items:

1. You can often communicate with supervisors/coworkers.

2. You can strongly rely on supervisors/co-workers when you have problems.

3. Your supervisors/co-workers are prepared to spend their time on dealing with your personal problems.

The responses to these items were scored on a 4-point Likert-type scale (1 - agree; 2 -somewhat agree; 3 - somewhat disagree, and 4 - disagree).

Job demand and job control scores were each dichotomized at a median value, and job strain was categorized as follows:

- high job strain was defined as present when job demand was high and job control was low,

- intermediate job strain was defined as present when job demand was high and job control was high, or vice versa,

- low job strain was defined as present when job demand was low and job control was high.

To evaluate social support from supervisors and co-workers, the total score was calculated for each of the 3 questions; higher scores denote higher social support [26]. Cronbach's $\alpha$ coefficients for the BJSQ subscales - job demand, job control, social support from supervisors and that from co-workers - were $0.82,0.73,0.92$ and 0.85 , respectively.

\section{Depressive symptoms}

Depressive symptoms were assessed with the Japanese version of Patient Health Questionnaire-9 (PHQ-9) [27], 
the depression subscale of the self-report Patient Health Questionnaire [28]. PHQ-9 consists of 9 items and the total score varies between 0 and 27 [29]. Standard PHQ-9 cut-off scores were used to classify minimal (0-4), mild (5-9) and moderate to severe ( $\geq 10$ ) symptoms of depression [30]. In this study, positive for depressive symptoms was defined as PHQ-9 scores $>5$ to identify mild mental health problems, because it is not common that active working medical doctors have a severe mental health problem. Cronbach's $\alpha$ coefficient for PHQ-9 was 0.88 .

\section{Burnout}

The Japanese version of the Maslach Burnout Inventory - General Survey (MBI-GS) was used to evaluate burnout [15,31-33]. MBI-GS has 16 items with 3 subscales: exhaustion (5 items), depersonalization (5 items) and professional efficacy (6 items). Each item was scored using a 7-point Likert-type scale ranging from 'never' ( 0 points) to 'every day' (6 points), based on the frequency of occurrence. The total scores for each subscale were divided by the number of items on the subscale; higher exhaustion and depersonalization scores and a lower professional efficacy score denote higher degrees of burnout. Cronbach's $\alpha$ coefficients for exhaustion, depersonalization and professional efficacy were $0.92,0.87$ and 0.87 , respectively.

Each subscale was tertilized because the cut-offs of Japanese general population have not been estimated. The cut-offs of exhaustion, depersonalization and professional efficacy were 4.2, 2.4, and 2.5, respectively, and the upper tertiles of exhaustion and depersonalization and the lower tertile of professional efficacy were defined as subscale positives. Then, on the basis of the common burnout process indicating that exhaustion comes first, followed by depersonalization and diminished professional efficacy, the participants having at least exhaustion positive and having either depersonalization positive or professional efficacy positive were defined as burnout positive $[34,35]$.

\section{Statistical analysis}

Crude odds ratios of demographics, work-related factors, job strain and social support from supervisors and coworkers for depressive symptoms and burnout were analyzed by a univariate logistic regression analysis. Then, we conducted multivariate logistic regression analyses with depressive symptoms and burnout as dependent variables adjusted for sex, marital status, clinical experience, place of work, location and specialty. Because 'clinical experience' had stronger relationships than 'age' in the univariate analyses, 'clinical experience' was introduced in the models as an adjusted variable. Since the workload variables such as 'days off,' 'night duty,' 'on call' and 'working hours per week' may be intermediate variables of 'job demand,' we analyzed the following 2 models:

- model 1 - 'days off,' 'night duty,' 'on call,' 'working hours per week,' 'support from supervisors' and 'support from co-workers;'

- model 2 - 'job strain,' 'support from supervisors' and 'support from co-workers.'

To confirm interaction effect between job strain and support, interaction terms between job strain and support from supervisors, and job strain and support from coworkers were also analyzed.

$\mathrm{P}$ values $<0.05$ were considered statistically significant. All calculations were conducted using IBM SPSS Statistics 21.0 for Windows (SPSS Inc., Chicago, IL, USA).

\section{RESULTS}

Table 1 shows the demographic and work-related factors, each score on the BJSQ item, each score on the MBI-GS item, PHQ-9 score, job strain category, depressive symptom positive (PHQ-9 > 5) and burnout positive.

Table 2 shows the crude odds ratio of each variable for depressive symptoms and burnout. Age, clinical experience, days off, night duty, working hours, job strain and support from co-workers were significantly related 
Table 1. Participants' characteristics

\begin{tabular}{|c|c|c|c|}
\hline Variable & $\begin{array}{l}\text { Respondents } \\
(\mathrm{N}=488)\end{array}$ & Variable & $\begin{array}{l}\text { Respondents } \\
(\mathrm{N}=488)\end{array}$ \\
\hline Men [n (\%)] & $391(80.1)$ & Night duty shifts per month $[\mathrm{n}(\%)]$ - cont. & \\
\hline Age (years) $[\mathrm{n}(\%)]$ & & $2-3$ & $116(23.8)$ \\
\hline$\leq 29$ & $32(6.6)$ & $4-5$ & $79(16.2)$ \\
\hline $30-39$ & $101(20.7)$ & $\geq 6$ & $50(10.2)$ \\
\hline $40-49$ & $196(40.2)$ & On call shifts per month & \\
\hline$\geq 50$ & $159(32.6)$ & none & $222(45.5)$ \\
\hline Married $[\mathrm{n}(\%)]$ & $373(76.4)$ & $1-4$ & $94(19.3)$ \\
\hline Clinical experience (years) [n (\%)] & & $5-7$ & $75(15.4)$ \\
\hline$\leq 9$ & $76(15.6)$ & $\geq 8$ & $97(19.9)$ \\
\hline $10-19$ & $164(33.6)$ & Working hours per week $[\mathrm{n}(\%)]$ & \\
\hline$\geq 20$ & $248(50.8)$ & $0-39$ & $31(6.4)$ \\
\hline Place of work $[\mathrm{n}(\%)]$ & & $40-49$ & $89(18.2)$ \\
\hline hospital & $409(83.8)$ & $50-59$ & $97(19.9)$ \\
\hline clinic & $79(16.2)$ & $60-79$ & $173(35.5)$ \\
\hline Location $[\mathrm{n}(\%)]$ & & $\geq 80$ & $98(20.1)$ \\
\hline large city & $304(62.3)$ & Job stress $(\mathrm{M} \pm \mathrm{SD})$ & \\
\hline medium or small city & $135(27.7)$ & demand & $9.1 \pm 2.3$ \\
\hline town or village & $49(10.0)$ & control & $8.3 \pm 2.1$ \\
\hline Specialty $[\mathrm{n}(\%)]$ & & support from supervisors & $6.6 \pm 2.8$ \\
\hline internal medicine & $186(38.1)$ & support from co-workers & $7.8 \pm 2.3$ \\
\hline surgery & $136(27.9)$ & Job strain & \\
\hline pediatrics/obstetrics/gynecology & $51(10.5)$ & low $[\mathrm{n}(\%)]$ & $76(15.6$ \\
\hline ophthalmology/dermatology & $43(8.8)$ & medium $[\mathrm{n}(\%)]$ & $244(50.0)$ \\
\hline other/unknown & $72(14.8)$ & $\operatorname{high}[\mathrm{n}(\%)]$ & $168(34.4)$ \\
\hline Days off per month [n (\%)] & & PHQ-9 (M \pm SD) & $4.8 \pm 4.7$ \\
\hline none or 1 & $75(15.4)$ & PHQ-9 $\geq 5[\mathrm{n}(\%)]$ & $198(40.6)$ \\
\hline $2-4$ & $235(48.2)$ & Burnout & \\
\hline $5-7$ & $123(25.2)$ & & $3.1 \pm 1.6$ \\
\hline$\geq 8$ & $55(11.3)$ & reduced professional efficacy $(\mathrm{M} \pm \mathrm{SD})$ & $3.2 \pm 1.4$ \\
\hline Night duty shifts per month [n (\%)] & & burnout positive [n (\%)] & $108(22.1)$ \\
\hline 1 & $61(12.5)$ & \multicolumn{2}{|c|}{$\begin{array}{l}\text { M - mean; SD - standard deviation; PHQ - Patient Health Ques } \\
\text { tionnaire. }\end{array}$} \\
\hline
\end{tabular}


to depressive symptoms, and age, clinical experience, days off, night duty, on call, working hours, job strain and support from co-workers were significantly related to burnout.

Table 3 shows the multivariate adjusted odds ratio for depressive symptoms. High job strain had significantly higher odds ratios in model 2, and support from supervisors and co-workers had significant protective odds ratios in all models. We also introduced interaction terms in model 2, and the interaction terms between job strain and support from supervisors, and job strain and support from coworkers had no statistically significant results.

Table 2. Crude odds ratio for depressive symptoms (PHQ-9 > 5) and burnout

\begin{tabular}{|c|c|c|c|c|c|c|}
\hline \multirow{2}{*}{ Variable } & \multicolumn{3}{|c|}{ Depressive symptoms } & \multicolumn{3}{|c|}{ Burnout } \\
\hline & OR & $95 \% \mathrm{CI}$ & $\mathrm{p}$ & OR & $95 \% \mathrm{CI}$ & $\mathrm{p}$ \\
\hline Men (vs. women) & 0.71 & $0.45-1.10$ & 0.126 & 0.96 & $0.57-1.64$ & 0.884 \\
\hline \multicolumn{7}{|l|}{ Age (years) } \\
\hline$\leq 29$ & 1.00 & & & 1.00 & & \\
\hline $30-39$ & 0.55 & $0.25-1.24$ & 0.149 & 1.58 & $0.62-4.04$ & 0.338 \\
\hline $40-49$ & 0.56 & $0.26-1.19$ & 0.131 & 1.03 & $0.42-2.55$ & 0.942 \\
\hline$\geq 50$ & 0.42 & $0.20-0.91$ & 0.029 & 0.70 & $0.27-1.78$ & 0.453 \\
\hline Married (vs. unmarried) & 0.68 & $0.45-1.03$ & 0.071 & 0.59 & $0.37-0.95$ & 0.029 \\
\hline \multicolumn{7}{|l|}{ Clinical experience (years) } \\
\hline$\leq 9$ & 1.00 & & & 1.00 & & \\
\hline 10-19 & 0.63 & $0.36-1.09$ & 0.096 & 0.68 & $0.38-1.23$ & 0.204 \\
\hline$\geq 20$ & 0.46 & $0.27-0.77$ & 0.003 & 0.35 & $0.20-0.64$ & 0.001 \\
\hline Hospital (vs. clinic) & 2.02 & $1.19-3.42$ & 0.009 & 3.37 & $1.50-7.57$ & 0.003 \\
\hline \multicolumn{7}{|l|}{ Location } \\
\hline large city & 1.00 & & & 1.00 & & \\
\hline medium or small city & 0.90 & $0.60-1.37$ & 0.621 & 0.68 & $0.41-1.14$ & 0.148 \\
\hline town or village & 0.81 & $0.43-1.51$ & 0.506 & 0.92 & $0.45-1.88$ & 0.811 \\
\hline \multicolumn{7}{|l|}{ Specialty } \\
\hline internal medicine & 1.00 & & & 1.00 & & \\
\hline surgery & 0.77 & $0.49-1.23$ & 0.275 & 0.61 & $0.34-1.08$ & 0.090 \\
\hline pediatrics/obstetrics/gynecology & 1.35 & $0.72-2.51$ & 0.351 & 0.81 & $0.38-1.75$ & 0.594 \\
\hline ophthalmology/dermatology & 1.20 & $0.61-2.34$ & 0.597 & 1.14 & $0.53-2.46$ & 0.732 \\
\hline other/unknown & 1.43 & $0.83-2.48$ & 0.199 & 1.56 & $0.86-2.85$ & 0.147 \\
\hline \multicolumn{7}{|l|}{ Days off per month } \\
\hline none or 1 & 2.90 & $1.37-6.10$ & 0.005 & 4.15 & $1.46-11.80$ & 0.008 \\
\hline $2-4$ & 1.87 & $0.98-3.58$ & 0.057 & 3.43 & $1.31-9.00$ & 0.012 \\
\hline $5-7$ & 1.65 & $0.82-3.31$ & 0.159 & 2.06 & $0.73-5.78$ & 0.170 \\
\hline$\geq 8$ & 1.00 & & & 1.00 & & \\
\hline
\end{tabular}


Table 2. Crude odds ratio for depressive symptoms (PHQ-9 > 5) and burnout - cont.

\begin{tabular}{|c|c|c|c|c|c|c|}
\hline \multirow{2}{*}{ Variable } & \multicolumn{3}{|c|}{ Depressive symptoms } & \multicolumn{3}{|c|}{ Burnout } \\
\hline & OR & $95 \% \mathrm{CI}$ & $\mathrm{p}$ & $\mathrm{OR}$ & $95 \% \mathrm{CI}$ & $\mathrm{p}$ \\
\hline \multicolumn{7}{|l|}{ Night duty shifts per month } \\
\hline none & 1.00 & & & 1.00 & & \\
\hline 1 & 1.66 & $0.92-3.00$ & 0.096 & 1.12 & $0.52-2.39$ & 0.780 \\
\hline $2-3$ & 1.64 & $1.01-2.64$ & 0.045 & 1.69 & $0.95-3.00$ & 0.074 \\
\hline $4-5$ & 2.03 & $1.19-3.49$ & 0.010 & 2.08 & $1.12-3.88$ & 0.021 \\
\hline$\geq 6$ & 1.64 & $0.87-3.10$ & 0.130 & 2.17 & $1.06-4.46$ & 0.035 \\
\hline \multicolumn{7}{|l|}{ On call shifts per month } \\
\hline none & 1.00 & & & 1.00 & & \\
\hline $1-4$ & 1.00 & $0.61-1.64$ & 0.999 & 1.23 & $0.67-2.24$ & 0.500 \\
\hline $5-7$ & 1.28 & $0.75-2.15$ & 0.383 & 0.66 & $0.89-3.06$ & 0.109 \\
\hline$\geq 8$ & 1.34 & $0.83-2.17$ & 0.237 & 1.85 & $1.06-3.22$ & 0.031 \\
\hline \multicolumn{7}{|l|}{ Working hours per week } \\
\hline 0-39 & 1.10 & $0.45-2.63$ & 0.842 & 0.95 & $0.28-3.12$ & 0.935 \\
\hline $40-49$ & 1.00 & & & 1.00 & & \\
\hline $50-59$ & 1.08 & $0.58-2.01$ & 0.812 & 0.91 & $0.38-2.14$ & 0.821 \\
\hline $60-79$ & 2.22 & $1.29-3.81$ & 0.004 & 2.46 & $1.23-4.93$ & 0.011 \\
\hline$\geq 80$ & 1.95 & $1.07-3.26$ & 0.030 & 3.11 & $1.49-6.52$ & 0.003 \\
\hline \multicolumn{7}{|l|}{ Job strain } \\
\hline low & 1.00 & & & 1.00 & & \\
\hline medium & 2.47 & $1.34-4.55$ & 0.004 & 3.53 & $1.22-10.21$ & 0.020 \\
\hline high & 3.84 & $2.05-7.20$ & $<0.001$ & 11.08 & $3.86-31.78$ & $<0.001$ \\
\hline Support from supervisors & 0.96 & $0.90-1.03$ & 0.258 & 0.98 & $0.91-1.06$ & 0.567 \\
\hline Support from co-workers & 0.88 & $0.82-0.96$ & 0.003 & 0.86 & $0.78-0.95$ & 0.002 \\
\hline
\end{tabular}

PHQ - Patient Health Questionnaire; OR - odds ratio; CI - confidence interval.

Table 3. Adjusted odds ratio for depressive symptoms (PHQ-9 > 5)

\begin{tabular}{|c|c|c|c|c|c|c|}
\hline \multirow{2}{*}{ Variable } & \multicolumn{3}{|c|}{ Model 1} & \multicolumn{3}{|c|}{ Model 2} \\
\hline & OR & $95 \% \mathrm{CI}$ & $\mathrm{p}$ & OR & $95 \% \mathrm{CI}$ & $\mathrm{p}$ \\
\hline \multicolumn{7}{|l|}{ Days off per month } \\
\hline none or 1 & 2.19 & $0.79-6.04$ & 0.131 & & & \\
\hline $2-4$ & 1.75 & $0.75-4.10$ & 0.196 & & & \\
\hline $5-7$ & 1.62 & $0.70-3.79$ & 0.263 & & & \\
\hline$\geq 8$ & 1.00 & & & & & \\
\hline
\end{tabular}


Table 3. Adjusted odds ratio for depressive symptoms (PHQ-9 > 5) - cont.

\begin{tabular}{|c|c|c|c|c|c|c|}
\hline \multirow{2}{*}{ Variable } & \multicolumn{3}{|c|}{ Model 1} & \multicolumn{3}{|c|}{ Model 2} \\
\hline & OR & $95 \% \mathrm{CI}$ & $\mathrm{p}$ & OR & $95 \% \mathrm{CI}$ & $\mathrm{p}$ \\
\hline \multicolumn{7}{|l|}{ Night duty shifts per month } \\
\hline none & 1.00 & & & & & \\
\hline 1 & 1.27 & $0.61-2.65$ & 0.520 & & & \\
\hline $2-3$ & 1.09 & $0.58-2.06$ & 0.779 & & & \\
\hline $4-5$ & 1.60 & $0.82-3.14$ & 0.168 & & & \\
\hline$\geq 6$ & 1.19 & $0.53-2.68$ & 0.667 & & & \\
\hline \multicolumn{7}{|l|}{ On call shifts per month } \\
\hline none & 1.00 & & & & & \\
\hline $1-4$ & 0.94 & $0.54-1.64$ & 0.838 & & & \\
\hline $5-7$ & 0.94 & $0.50-1.75$ & 0.840 & & & \\
\hline$\geq 8$ & 0.97 & $0.54-1.75$ & 0.931 & & & \\
\hline \multicolumn{7}{|l|}{ Working hours per week } \\
\hline 0-39 & 1.00 & $0.37-2.74$ & 0.999 & & & \\
\hline $40-49$ & 1.00 & & & & & \\
\hline $50-59$ & 0.87 & $0.44-1.74$ & 0.698 & & & \\
\hline $60-79$ & 1.80 & $0.92-3.52$ & 0.086 & & & \\
\hline$\geq 80$ & 1.46 & $0.68-3.16$ & 0.333 & & & \\
\hline \multicolumn{7}{|l|}{ Job strain } \\
\hline low & & & & 1.00 & & \\
\hline medium & & & & 2.12 & $1.10-4.10$ & 0.025 \\
\hline high & & & & 3.43 & $1.72-6.85$ & $<0.001$ \\
\hline Support from supervisors & 0.90 & $0.82-0.99$ & 0.035 & 0.91 & $0.82-0.99$ & 0.038 \\
\hline$\underline{\text { Support from co-workers }}$ & 0.88 & $0.79-0.97$ & 0.011 & 0.88 & $0.80-0.97$ & 0.013 \\
\hline
\end{tabular}

Adjusted for sex, marital status, clinical experience, place of work, location and specialty. Model 1 - includes days off, night duty, on call, working hours, support from supervisors and support from co-workers. Model 2 - includes job strain, support from supervisors and support from co-workers. Abbreviations as in Table 2.

Table 4 shows the multivariate adjusted odds ratio for burnout. Compared with $\geq 8$ days off per month, 2-4 days off per month had significantly higher odds ratios in model 1, and high job strain had significantly higher odds ratios in model 2 , as support from co-workers had significant protective odds ratios in all models. In addition to this, the interaction terms between job strain and support from supervisors, and job strain and support from co-workers had no statistical significant results.

\section{DISCUSSION}

The purposes of this study were to elucidate whether job strain and job factors affect physicians' mental health, and whether support from supervisors and co-workers has a protective effect on their mental health, and we found significant relationships between job strain and support from co-workers and both depressive symptoms and burnout, and a significant relationship between days off and burnout, among Japanese physicians. The results were consistent with several previous reports [10,36,37]. 
Table 4. Adjusted odds ratio for burnout

\begin{tabular}{|c|c|c|c|c|c|c|}
\hline \multirow{2}{*}{ Variable } & \multicolumn{3}{|c|}{ Model 1} & \multicolumn{3}{|c|}{ Model 2} \\
\hline & OR & $95 \% \mathrm{CI}$ & $\mathrm{p}$ & OR & $95 \% \mathrm{CI}$ & $\mathrm{p}$ \\
\hline \multicolumn{7}{|l|}{ Days off per month } \\
\hline none or 1 & 3.61 & $0.91-14.32$ & 0.068 & & & \\
\hline $2-4$ & 3.69 & $1.09-12.51$ & 0.036 & & & \\
\hline $5-7$ & 2.10 & $0.62-7.14$ & 0.236 & & & \\
\hline$\geq 8$ & 1.00 & & & & & \\
\hline \multicolumn{7}{|l|}{ Night duty shifts per month } \\
\hline none & 1.00 & & & & & \\
\hline 1 & 0.43 & $0.17-1.13$ & 0.087 & & & \\
\hline $2-3$ & 0.67 & $0.31-1.45$ & 0.310 & & & \\
\hline $4-5$ & 1.09 & $0.48-2.48$ & 0.828 & & & \\
\hline$\geq 6$ & 0.88 & $0.35-2.26$ & 0.796 & & & \\
\hline \multicolumn{7}{|l|}{ On call shifts per month } \\
\hline none & 1.00 & & & & & \\
\hline $1-4$ & 1.23 & $0.63-2.42$ & 0.542 & & & \\
\hline $5-7$ & 1.23 & $0.59-2.54$ & 0.585 & & & \\
\hline$\geq 8$ & 1.48 & $0.75-2.94$ & 0.258 & & & \\
\hline \multicolumn{7}{|l|}{ Working hours per week } \\
\hline $0-39$ & 0.88 & $0.22-3.52$ & 0.856 & & & \\
\hline $40-49$ & 1.00 & & & & & \\
\hline $50-59$ & 0.59 & $0.22-1.55$ & 0.283 & & & \\
\hline $60-79$ & 1.56 & $0.65-3.74$ & 0.317 & & & \\
\hline$\geq 80$ & 1.74 & $0.66-4.54$ & 0.259 & & & \\
\hline \multicolumn{7}{|l|}{ Job strain } \\
\hline low & & & & 1.00 & & \\
\hline medium & & & & 2.49 & $0.82-7.59$ & 0.109 \\
\hline high & & & & 9.38 & $3.08-28.60$ & $<0.001$ \\
\hline Support from supervisors & 0.90 & $0.80-1.01$ & 0.061 & 0.90 & $0.80-1.02$ & 0.098 \\
\hline Support from co-workers & 0.84 & $0.74-0.96$ & 0.008 & 0.83 & $0.74-0.95$ & 0.005 \\
\hline
\end{tabular}

Adjusted for sex, marital status, clinical experience, place of work, location and specialty.

Abbreviations as in Tables 2 and 3.

A meta-analysis of general workers has reported that job strain has a significantly higher odds ratio for depression [38]. In a study of German junior doctors, job autonomy was significantly related to depressive symptoms [10]. In a study of Finnish general practitioners, job demand was significantly related to psychological distress assessed using the self-administered 12-item General Health Questionnaire (GHQ-12) [36]. Thus, several studies have reported relationships between demand and control and mental health problems; however, to our knowledge, there 
have been few reports on the relationship between job strain itself and mental health problems among physicians. In the present study, job strain was significantly related to depressive symptoms even after controlling for support from supervisors and co-workers. The previous metaanalysis showed that the risk of mental health problems was higher in association with high job strain rather than its constituents, which was speculated to be so because the composite measure captured the adverse work conditions better [38]. Thus, the assessment of physicians' job strain may be a relatively easy-to-use tool for the prevention of physicians' mental health problems.

As previously mentioned, burnout is a significant mental health indicator because physicians with a high risk of burnout tend to have the intention to change jobs [17], be affected by job dissatisfaction [18] and provide low-quality patient care $[19,20]$. Among dentists, high job strain has a significantly higher odds ratio for burnout [39]. Moreover, significant relationships of job demand and control and each burnout subscale have been reported among nurses [40]. There have also been some reports on the relationship between job strain and burnout among physicians. However, since a significant relationship between job strain and burnout was found in our present study, in addition to a relationship with depressive symptoms, physicians' job strain may be a good assessment tool for the prevention of mental health problems.

A meta-analysis has reported that low support from supervisors and co-workers has significantly higher odds ratios, with almost the same values for stress-related disorders estimated by GHQ-12 and the Checklist of Individual Strength $(\mathrm{CIS})$ (pooled odds ratio $=1.24$ ) [41]. A review of factors affecting U.S. physicians' job satisfaction reported that job support from colleagues was consistently related to job satisfaction in 5 studies, but support from supervisors was not found in the literature search [42]. In our present study, only support from co-workers had a significant association with both depressive symptoms and burnout. Further studies are needed to clarify whether support from co-workers has a greater buffering effect on mental health than support from supervisors.

A recent study of Japanese hospital doctors has reported that a depressive state is positively associated with being on call for more than 5 days per month for men and for more than 8 days per month for women, and is negatively associated with having more than 8 days off per month for men [7]. In our present study, only 2-4 days off per month had a significantly higher odds ratio for burnout. The recent Japanese study had a larger sample size $(\mathrm{N}=3862)$, although it did not control for specialty, marital status, working hours, and social support. The adjusted odds ratio of none or 1 day off per month in our present study was greater than 2, although this was not statistically significant. Therefore, days off may be an important factor for physicians' mental health, as the recent Japanese Hospital study found a significant result.

The adjusted odds ratio for burnout of having none or 1 day off per month was not statistically significant. It has been speculated that physicians have a greater ability to change their stress status because they can easily change hospitals/clinics, compared with other workers in Japan [43]. Thus, the work burden effect may have been attenuated because physicians who were able to work long hours as their nature tended to continue their long work hours.

The effects of on call and night duty were not significant in the adjusted analyses. We did not ask the participants about burdens such as number of patients or sleeping time per duty. The variety of their burden probably attenuated these results.

As previously mentioned, Japanese hospital physicians tend to be affected by long working hours [2,3] and the shortage of some specialties [4], and a recent study of Japanese hospital doctors has reported that a depressive state is negatively associated with having more than 8 days off per month for men [7]. In our present study, only 2-4 days 
off per month, job strain and support from co-workers were the statistically significant related factors. Thus, for physicians who feel overworked in Japan, an adequate number of days off is needed. Because of easy accessibility, assessment of job strain and support from co-workers are preferable to prevent mental health problems.

This study has several limitations. First, since this study was cross-sectional, we could not infer cause-effect relationships. Second, the response rate was relatively low. There might have been a tendency of not participating among physicians with greater job stress, which may have attenuated the significance of the results. Moreover, as previously mentioned, the work burden effect may have been attenuated. Also, we cannot present the characteristics of the non-respondents because we had only names and address data when we distributed the questionnaires. Therefore, we cannot present the characteristic differences between respondents and non-respondents. Third, doctors who participated in this study were alumni of one medical university. However, their workplaces (hospitals/ clinics) were distributed throughout Japan.

\section{CONCLUSIONS}

In conclusion, our results suggest that high job strain is related to depressive symptoms and burnout, and that higher social support, especially that from co-workers, has a buffering effect on depressive symptoms and burnout. Additionally, having an insufficient number of days off is related to burnout. Assessment of job strain may be a good tool to measure physicians' mental health, and a sufficient number of days off may be needed to improve physicians' burnout.

\section{REFERENCES}

1. Shanafelt TD, Sloan JA, Habermann TM. The well-being of physicians. Am J Med. 2003;114(6):513-9.
2. Ehara A. Labor law violations in Japanese public hospitals from March 2002 to March 2011. Pediatr Int. 2012;55(1): 90-5, http://dx.doi.org/10.1111/j.1442-200X.2012.03742.x.

3. Hiyama T, Yoshihara M. New occupational threats to Japanese physicians: Karoshi (death due to overwork) and karojisatsu (suicide due to overwork). Occup Environ Med. 2008;65(6): 428-9, http://dx.doi.org/10.1136/oem.2007.037473.

4. Wada K, Arimatsu M, Yoshikawa T, Oda S, Taniguchi H, Higashi T, et al. Factors on working conditions and prolonged fatigue among physicians in Japan. Int Arch Occup Environ Health. 2008;82(1):59-66, http://dx.doi.org/10.1007/ s00420-008-0307-3.

5. Virtanen M, Ferrie JE, Singh-Manoux A, Shipley MJ, Stansfeld SA, Marmot MG, et al. Long working hours and symptoms of anxiety and depression: A 5-year follow-up of the Whitehall II study. Psychol Med. 2011;41(12):2485-94, http://dx.doi.org/10.1017/s0033291711000171.

6. Tomioka K, Morita N, Saeki K, Okamoto N, Kurumatani N. Working hours, occupational stress and depression among physicians. Occup Med (Lond). 2011;61(3):163-70, http:// dx.doi.org/10.1093/occmed/kqr004.

7. Wada K, Yoshikawa T, Goto T, Hirai A, Matsushima E, Nakashima $Y$, et al. National survey of the association of depressive symptoms with the number of off duty and on-call, and sleep hours among physicians working in Japanese hospitals: A cross sectional study. BMC Public Health. 2010;10:127, http://dx.doi.org/10.1186/1471-2458-10-127.

8. Hayasaka Y, Nakamura K, Yamamoto M, Sasaki S. Work environment and mental health status assessed by the general health questionnaire in female Japanese doctors. Ind Health. 2007;45(6):781-6.

9. Karasek R. Job demands, job decision latitude, and mental strain: Implication for job resign. Adm Sci Q. 1979;24:285-309.

10. Weigl M, Hornung S, Petru R, Glaser J, Angerer P. Depressive symptoms in junior doctors: A follow-up study on work-related determinants. Int Arch Occup Environ Health. 2011;85(5):559-70, http://dx.doi.org/10.1007/s00420011-0706-8. 
11. Shields M. Stress and depression in the employed population. Health Rep. 2006;17(4):11-29.

12. Lee RT, Lovell BL, Brotheridge CM. Tenderness and steadiness: Relating job and interpersonal demands and resources with burnout and physical symptoms of stress in Canadian physicians. J Appl Soc Psychol. 2010;40(9):2319-42, http:// dx.doi.org/10.1111/j.1559-1816.2010.00658.x.

13. Klein J, Grosse Frie K, Blum K, von dem Knesebeck O. Psychosocial stress at work and perceived quality of care among clinicians in surgery. BMC Health Serv Res. 2011; 11:109, http://dx.doi.org/10.1186/1472-6963-11-109.

14. Stansfeld SA, Fuhrer R, Shipley MJ, Marmot MG. Work characteristics predict psychiatric disorder: Prospective results from the Whitehall II Study. Occup Environ Med. 1999;56(5):302-7.

15. Maslach C, Jackson SE. The measurement of experienced burnout. J Organ Behav. 1981;2(2):99-113, http://dx.doi. org/10.1002/job.4030020205.

16. Maslach C, Schaufeli WB, Leiter MP. Job burnout. Ann Rev Psychol. 2001;52:397-422, http://dx.doi.org/10.1146/annurev. psych.52.1.397.

17. Soler JK, Yaman H, Esteva M, Dobbs F, Asenova RS, Katic M, et al. Burnout in European family doctors: The EGPRN study. Fam Pract. 2008;25(4):245-65, http:// dx.doi.org/10.1093/fampra/cmn038.

18. Becker JL, Milad MP, Klock SC. Burnout, depression, and career satisfaction: Cross-sectional study of obstetrics and gynecology residents. Am J Obstet Gynecol. 2006;195(5):1444-9, http://dx.doi.org/10.1016/j.ajog. 2006.06.075.

19. Prins JT, van der Heijden FM, Hoekstra-Weebers JE, Bakker $A B$, van de Wiel HB, Jacobs B, et al. Burnout, engagement and resident physicians' self-reported errors. Psychol Health Med. 2009;14(6):654-66, http://dx.doi. org/10.1080/13548500903311554.

20. Shanafelt TD, Bradley KA, Wipf JE, Back AL. Burnout and self-reported patient care in an internal medicine residency program. Ann Intern Med. 2002;136(5):358-67.
21. Schaufeli WB, Leiter MP, Maslach C. Burnout: 35 years of research and practice. Career Dev Int. 2009;14(3):204-20.

22. Saijo Y, Chiba S, Yoshioka E, Kawanishi Y, Nakagi Y, Ito T, et al. Job stress and burnout among urban and rural hospital physicians in Japan. Aust J Rural Health. 2013;21(4): 225-31, http://dx.doi.org/10.1111/ajr.12040.

23. Shimomitsu T, Yokoyama K, Ohno H, Maruta T, Tanigawa T. Manual of the Brief Job Stress Questionnaire. In: Reports on the study of job stress and its effects on health in the workplace: The research grant for the prevention of workrelated diseases from the Japan Ministry of Labour. Tokyo: The Ministry of Labor; 2000.

24. Umehara K, Ohya Y, Kawakami N, Tsutsumi A, Fujimura M. Association of work-related factors with psychosocial job stressors and psychosomatic symptoms among Japanese pediatricians. J Occup Health. 2007;49(6):467-81.

25. Suwazono Y, Dochi M, Kobayashi E, Oishi M, Okubo Y, Tanaka K, et al. Benchmark duration of work hours for development of fatigue symptoms in Japanese workers with adjustment for job-related stress. Risk Anal. 2008;28(6):1689-98, http://dx.doi.org/10.1111/ j.1539-6924.2008.01107.x.

26. Kawada T, Otsuka T. Relationship between job stress, occupational position and job satisfaction using a brief job stress questionnaire (BJSQ). Work. 2011;40(4):393-9, http:// dx.doi.org/10.3233/wor-2011-1251.

27. Muramatsu K, Miyaoka H, Kamijima K, Muramatsu Y, Yoshida M, Otsubo T, et al. The patient health questionnaire, Japanese version: Validity according to the mini-international neuropsychiatric interview-plus. Psychol Rep. 2007;101(3 Pt 1):952-60.

28. Spitzer RL, Kroenke K, Williams JB. Validation and utility of a self-report version of PRIME-MD: The PHQ primary care study. Primary care evaluation of mental disorders. Patient Health Questionnaire. JAMA. 1999;282(18):1737-44.

29. Kroenke K, Spitzer RL, Williams JB. The PHQ-9: Validity of a brief depression severity measure. J Gen Intern Med. 2001;16(9):606-13. 
30. Roy T, Lloyd CE, Parvin M, Mohiuddin KG, Rahman M. Prevalence of co-morbid depression in out-patients with type 2 diabetes mellitus in Bangladesh. BMC Psychiatry. 2012;12:123, http://dx.doi.org/10.1186/1471-244x$12-123$.

31. Maslach C, Jackson SE, Leiter MP. Maslach Burnout Inventory mannual. 3rd ed. Menlo Park (CA): Mind Garden; 1996.

32. Kitaoka-Higashiguchi K, Nakagawa H, Morikawa Y, Ishizaki M, Miura K, Naruse Y, et al. Construct validity of the Maslach Burnout Inventory-General Survey. Stress Health. 2004;20(5):255-60, http://dx.doi.org/10.1002/ smi.1030.

33. Kitaoka-Higashiguchi K, Ogino K, Masuda S. [Validation of a Japanese research version of the Maslach Burnout Inventory-General Survey]. Jpn J Psychol. 2004;75(5):415-9. Japanese.

34. Brenninkmeijer V, VanYperen N. How to conduct research on burnout: Advantages and disadvantages of a unidimensional approach in burnout research. Occup Environ Med. 2003;60 Suppl 1:116-20.

35. Kitaoka-Higashiguchi K, Morikawa Y, Miura K, Sakurai $\mathrm{M}$, Ishizaki $\mathrm{M}$, Kido T, et al. Burnout and risk factors for arteriosclerotic disease: Follow-up study. J Occup Health. 2009;51(2):123-31.

36. Elovainio M, Salo P, Jokela M, Heponiemi T, Linna A, Virtanen $\mathrm{M}$, et al. Psychosocial factors and well-being among Finnish GPs and specialists: A 10-year follow-up.
Occup Environ Med. 2013;70(4):246-51, http://dx.doi. org/10.1136/oemed-2012-100996.

37. Lee RT, Seo B, Hladkyj S, Lovell BL, Schwartzmann L. Correlates of physician burnout across regions and specialties: A meta-analysis. Hum Resour Health. 2013;11:48, http://dx.doi.org/10.1186/1478-4491-11-48.

38. Stansfeld S, Candy B. Psychosocial work environment and mental health - A meta-analytic review. Scand J Work Environ Health. 2006;32(6):443-62.

39. Ahola K, Hakanen J. Job strain, burnout, and depressive symptoms: A prospective study among dentists. J Affect Disord. 2007;104(1-3):103-10, http://dx.doi.org/10.1016/ j.jad.2007.03.004.

40. Xie Z, Wang A, Chen B. Nurse burnout and its association with occupational stress in a cross-sectional study in Shanghai. J Adv Nurs. 2011;67(7):1537-46, http://dx.doi. org/10.1111/j.1365-2648.2010.05576.x.

41. Nieuwenhuijsen K, Bruinvels D, Frings-Dresen M. Psychosocial work environment and stress-related disorders, a systematic review. Occup Med (Lond). 2010;60(4):277-86, http://dx.doi.org/10.1093/occmed/kqq081.

42. Scheurer D, McKean S, Miller J, Wetterneck T. U.S. physician satisfaction: A systematic review. J Hosp Med. 2009;4(9):560-8, http://dx.doi.org/10.1002/jhm.496.

43. Kurihara N. [Overwork and mental health of doctors and other medical staff]. Occup Health Rev. 2007;19(4):247-69. Japanese.

This work is available in Open Access model and licensed under a Creative Commons Attribution-NonCommercial 3.0 Poland License - http://creativecommons.org/ licenses/by-nc/3.0/pl/deed.en. 